\title{
A Normative Study of the Disability Assessment for Dementia in Community-Dwelling Elderly Koreans
}

\author{
Jin Hyeong Jhoo', Yeon Kyung $\mathrm{Chi}^{2}$, Hyo Jung $\mathrm{Choi}^{2}$, Ji Won $\mathrm{Han}^{2}$, Tae Hui $\mathrm{Kim}^{3}$, \\ Jung Jae Lee ${ }^{4}$, Seok Bum Lee ${ }^{4}$, Joon Hyuk Park ${ }^{5}$, Jong Chul Youn ${ }^{6}$, Jeong Lan Kim, \\ Seung-Ho Ryu ${ }^{8}$, Dong Young Lee ${ }^{9,10}$, and Ki Woong Kim ${ }^{2,10,11} \bowtie$ \\ 'Department of Psychiatry, Kangwon National University School of Medicine, Chuncheon, Republic of Korea \\ ${ }^{2}$ Department of Neuropsychiatry, Seoul National University Bundang Hospital, Seongnam, Republic of Korea \\ ${ }^{3}$ Department of Psychiaty, Wonju Severance Christian Hospital, Wonju, Republic of Korea \\ ${ }^{4}$ Department of Psychiatry, Dankook University Hospital, Cheonan, Republic of Korea \\ ${ }^{5}$ Department of Neuropsychiatry, Jeju National University Hospital, Jeju, Republic of Korea \\ ${ }^{6}$ Department of Neuropsychiatry, Kyunggi Provincial Hospital for the Elderly, Yongin, Republic of Korea \\ ${ }^{7}$ Department of Psychiatry, Chungnam National University Hospital, Daejeon, Republic of Korea \\ ${ }^{8}$ Department of Neuropsychiatry, Konkuk University Hospital, Seoul, Republic of Korea \\ ${ }^{9}$ Department of Neuropsychiatry, Seoul National University Hospital, Seoul, Republic of Korea \\ ${ }^{10}$ Department of Psychiatry, Seoul National University College of Medicine, Seoul, Republic of Korea \\ ${ }^{11}$ Department of Brain and Cognitive Sciences, Seoul National University College of Natural Sciences, Seoul, Republic of Korea
}

Objective We investigated demographic influences on Korean version of Disability Assessment for Dementia (DAD-K) performance and developed normative data for DAD-K.

Methods The DAD-K was administered to 2362 normal controls (NCs), 296 patients with mild cognitive impairment (MCI) and 293 patients with Alzheimer's disease (AD). MANOVA and ROC curve analysis were used to compare DAD-K performance and the diagnostic accuracy of DAD-K, respectively. The demographic influence on DAD-K scores was analyzed by multiple linear regression and ANOVA. Normative DAD-K data were calculated using natural logarithmic transformation.

Results All DAD-K scores were significantly different among groups $(\mathrm{p}<0.001)$. Post hoc analysis showed that instrumental activities of daily living (IADL), executive function and DAD-K total scores began to decline significantly in the very mild stage of AD, whereas the basic activities of daily living (BADL) scores began to decline in the mild stage of AD. The area under the ROC curve differentiating $\mathrm{MCI}$ or $\mathrm{AD}$ from $\mathrm{NC}$ was 0.737 and that differentiating $\mathrm{AD}$ from $\mathrm{MCI}$ or NC was 0.911 . IADL and planning and organization scores were influenced by age and education and performance and DAD-K total scores were influenced by education.

Conclusion The demographic influences on DAD-K scores are not conspicuous and are mainly limited to the IADL and planning and organization scores. Unitary or minimally stratified norms for a specific population were developed for DAD-K application. Our results suggest that the $\mathrm{DAD}-\mathrm{K}$ is useful for differentiating NC or MCI from $\mathrm{AD}$ but not as powerful for differentiating NC from MCI.

Psychiatry Investig 2014;11(4):446-453

Key Words Norms, Disability Assessment for Dementia, Korean, Age, Education, Gender.

\section{INTRODUCTION}

Limitation in activities of daily living (ADL) is one of the

Received: October 1, 2013 Revised: November 30, 2013

Accepted: December 9, 2013 Available online: October 20, 2014

$\bowtie$ Correspondence: Ki Woong Kim, MD, PhD

Department of Neuropsychiatry, Seoul National University College of Medicine and Seoul National University Bundang Hospital, 166 Gumi-ro, Bundang-gu, Seongnam 463-707, Republic of Korea

Tel: +82-31-787-7432, Fax: +82-31-787-4058, E-mail: kwkimmd@snu.ac.kr

(a) This is an Open Access article distributed under the terms of the Creative Commons Attribution Non-Commercial License (http://creativecommons.org/licenses/bync/3.0) which permits unrestricted non-commercial use, distribution, and reproduction in any medium, provided the original work is properly cited. core features of dementia. Clinical differentiation among dementia, mild cognitive impairment (MCI) and normal cognitive aging is largely dependent on ADL assessment. For example, ADL should be intact for a diagnosis of MCI according to the original diagnostic criteria for MCI proposed by Petersen. ${ }^{1}$ However, as impairments in complex instrumental function were repeatedly reported in patients with $\mathrm{MCI},{ }^{2,3}$ minimal impairment in complex ADL, which is not severe enough to satisfy the threshold of dementia, is allowed in the revised MCI diagnostic criteria proposed by the International Working Group on MCI. ${ }^{4}$ Because cognitive function and 
processing speed are normally decreased to some extent in normal elders, complex ADL also can be minimally impaired in the elderly subjects without objective cognitive impairments on formal neuropsychological tests. ${ }^{5}$ The importance of evaluating ADL is not limited to differentiation of MCI from dementia or normal cognitive aging. Patients with $\mathrm{MCI}$ who exhibit minimal ADL impairments are more likely to progress to dementia ${ }^{6,7}$ and to have smaller hippocampal volumes than those without minimal ADL impairments. ${ }^{8}$ In addition, any degree of cognitive decline assessed by neuropsychological tests may have a measurable impact on a person's ability to function in daily life, provided instruments exist that are sensitive enough to document activity restriction. ${ }^{9-11}$ Moreover, impairments in executive function, which are often not detected by formal neuropsychological tests, are detected from the informant-based complex ADL test. ${ }^{5}$

As the assessment of ADL impairment has become important in diagnosing MCI and dementia, the requirements for developing sensitive and reliable instruments for evaluating ADL have increased. However, in both clinical and research settings, there is no agreement on the standard instruments of ADL assessment or the norms and cut-off values for determining minimal and/or significant impairments in ADL for diagnosing MCI and dementia. ${ }^{4}$ Various scales such as the ADL scale, ${ }^{12}$ the IADL scale, ${ }^{13}$ the Bayer ADL scale ${ }^{14}$ and related dimensions of the Clinical Dementia Rating (CDR) 2,4,9,10,15,16 as well as clinicians' judgments ${ }^{17}$ have been used to assess ADL in diagnosing MCI or dementia. However, there are no agreed upon normative data or cut-off values for defining minimal impairment. ${ }^{1}$ Complex instrumental ADL, in particular, may be influenced by demographic factors such as gender, education and age. These operational ambiguities in evaluating ADL might result in increased diagnostic heterogeneity and reduced predictive validity for outcomes. ${ }^{7}$

The Disability Assessment for Dementia (DAD) ${ }^{18}$ is an informant-based interview that has several strengths over other complex ADL scales in diagnosing and evaluating patients with MCI or dementia. First, it includes both instrumental and basic ADL items. Second, it evaluates which activities are problematic as well as which aspects of performance are impaired. ${ }^{18}$ Third, it is available in many languages including Korean, ${ }^{19-22}$ which facilitates multi-center and international studies. ${ }^{18}$ Therefore, in the present study, we hypothesized the Korean version of DAD (DAD-K) $)^{22}$ would be helpful in differentiating the NC or MCI from dementia and based on that hypothesis we examined the validity of DAD-K and established gender-, education-, and age-specific norms that may contribute to the development of a standard for evaluating ADL and studying MCI and dementia.

\section{METHODS}

\section{Participants}

The patient group consisted of 293 probable patients with Alzheimer's disease (AD) and 296 patients with MCI. We selected the patients from both the participants in the Korean Longitudinal Study on Health and Aging (KLOSCAD) ${ }^{23}$ and the visitors to the Dementia Clinics of Seoul National University Bundang Hospital from 2007 to 2011. The normal control (NC) group consisted of 2362 cognitively normal elders with a $\mathrm{CDR}^{24}$ score of 0 , who participated in KLOSCAD. The participants of the KLOSCAD were randomly sampled from the community-dwelling elderly Koreans aged 60 years or older using the residential rosters from 14 districts nationwidely. The subjects who had major Axis I psychiatric disorders and serious medical or neurological disorders that could affect their cognitive function were excluded. All subjects were community-dwelling Koreans aged 60 years or more who had adequate vision and hearing; however, many wore glasses, and some required a hearing aid. The written informed consent was obtained from all caregivers recruited in the study.

\section{Assessment}

A geropsychiatrist with advanced training in neuropsychiatry and dementia research examined each subject according to the protocol of the Korean version of the Consortium to Establish a Registry for Alzheimer's Disease (CERAD-K) Clinical Assessment Battery (CERAD-K-C) ${ }^{25}$ We interviewed reliable informants to acquire accurate information regarding subjects' cognitive and functional changes and medical histories. A panel of four research geropsychiatrists determined diagnoses and CDRs. We diagnosed probable AD according to the criteria of the National Institute of Neurological and Communicative Disorders and Stroke and the Alzheimer's Disease and Related Disorders Association (NINCDS-ADRDA). ${ }^{26}$ Patients with $\mathrm{AD}$ were classified into four groups using $\mathrm{CDR}$ : very mild $(\mathrm{CDR}=0.5)$, mild $(\mathrm{CDR}=1)$, moderate $(\mathrm{CDR}=2)$, and severe $(\mathrm{CDR}=3)$. We diagnosed $\mathrm{MCI}$ according to the International Working Group on MCI. ${ }^{4}$ Trained research nurses and psychologists administered the DAD-K, ${ }^{27}$ the Korean version of the geriatric depression scale (GDS-KR), ${ }^{28}$ the Korean version of Mini-Mental Status Examination (MMSE) ${ }^{29}$ and the subjective memory complaints questionnaire (SMCQ) $)^{30}$ to each subject.

The DAD-K consists of basic activities (BADL) such as hygiene, dressing, continence and eating and instrumental activities (IADL) including meal preparation, telephoning, going on an outing, finance and correspondence, medication, leisure and house work. Furthermore, each activity was evaluated according to three executive factors: initiation, planning-organi- 
zation and performance. The scores of all the items were calculated as percent scores (\%).

\section{Statistical analysis}

Descriptive statistics were used to determine whether there were differences in the subjects' demographic and clinical characteristics. Multivariate analysis of variance (MANOVA) and chi-square tests were used to compare demographics among the $\mathrm{NC}, \mathrm{MCI}$, and $\mathrm{AD}$ groups. Multivariate analysis of covariance (MANCOVA), adjusted for demographic and clinical characteristics, was used to compare DAD-K performance among the three groups. The receiver operating characteristic (ROC) curve analysis was used to compare the diagnostic accuracy of DAD-K and to determine optimal cut-off scores.

We performed multiple linear regression analyses with stepwise variable selection to assess the relative contribution of age, education and gender on DAD-K scores. Age and education were entered as continuous variables and gender was coded as 1 or 2 for male or female, respectively. The criteria for variable entry and removal were $\mathrm{p}<0.05$ and $\mathrm{p}<0.1$, respectively. We then performed a series of $3 \times 6$ analysis of variance (ANOVA) to determine any main effects and interactions of age (60-69, 70-79, and $\geq 80$ years) and education $(0,1-3,4-6$, $7-9,10-12$, and $\geq 13$ years) on the DAD-K. We divided age into three strata considering the number of subjects in each strata and education into six levels according to the Korean educational system. To maximize the quantity of information and the clinical usefulness of the data, we used overlapping strata for developing the normative data following Pauker's procedural descriptions. ${ }^{31}$ Normative data of BADL, IADL, initiation score, planning and organization score, performance score and DAD-K total score were presented. To develop DAD-K norms, data of NCs was calculated as a natural logarithmic transformation because the data was highly negatively skewed and did not follow a normal distribution. Thereafter, all data was re-transformed into natural numbers for conve- nience.

\section{RESULTS}

Subjects' demographic and clinical characteristics are shown in Table 1. Age, education, gender as well as MMSE, GDS-KR and SMCQ scores were significantly different among the six groups $(\mathrm{p}<0.001)$. Therefore, we performed MANCOVA using age, education, gender and GDS-KR score as covariates to compare DAD-K scores among the three groups (Table 2). All DAD-K subscale scores were significantly different among the groups $(\mathrm{p}<0.001)$. The post hoc analysis results are summarized in Table 2. The IADL scores began to decline significantly as the CDR increased starting from the very mild stage of $\mathrm{AD}$, whereas the BADL scores declined from the mild stage of $\mathrm{AD}$. Initiation, planning and organization, and performance scores also began to decline significantly as the CDR increased from the very mild stage of $\mathrm{AD}$.

We summarized the area under ROC curve (AUC) and optimal cut-off scores for AD and MCI in Table 3. The AUC of the DAD-K total score differentiating MCI or AD from NC was $0.737(95 \% \mathrm{CI}=0.710-0.763)$ and sensitivity and specificity at its optimal cut-off were 0.964 and 0.497 , respectively. The AUC of the DAD-K total score for differentiating AD from MCI or NC was 0.911 (95\% CI=0.885-0.937) and sensitivity and specificity at its optimal cut-off were 0.936 and 0.824 , respectively. The AUC of the DAD-K total score for differentiating $\mathrm{MCI}$ from NC was too low $(\mathrm{AUC}=0.549,95 \% \mathrm{CI}=0.512-$ 0.586).

Demographic characteristics of NCs who were enrolled in establishing normative data are shown in Table 4. Age was comparable between men and women (69.23 years vs. 69.58 years, $\mathrm{t}=-1.342, \mathrm{p}=0.180$ ). Men were more educated than women (11.16 years vs. 7.13 years, $t=20.202, p<0.001$ ).

In the Pearson's correlation analysis, age was highly correlated with the IADL score and planning and organization $(r=$ $-0.046, \mathrm{p}=0.024$ and $\mathrm{r}=-0.060, \mathrm{p}=0.003$, respectively). Age was

Table 1. Demographic and clinical characteristics of the participants

\begin{tabular}{|c|c|c|c|c|c|c|c|c|}
\hline & \multirow{2}{*}{$\mathrm{NC}^{\mathrm{a}}$} & \multirow{2}{*}{$\mathrm{MCI}^{\mathrm{b}}$} & \multicolumn{5}{|c|}{$\mathrm{AD}$} & \multirow{2}{*}{ Posthoc } \\
\hline & & & CDR $0.5^{c}$ & $\mathrm{CDR} 1^{\mathrm{d}}$ & $\mathrm{CDR} 2^{\mathrm{e}}$ & $\mathrm{CDR} \geq 3^{\mathrm{f}}$ & Total & \\
\hline Number (\%) & $2362(80.0)$ & $296(10.0)$ & $78(2.6)$ & $142(4.8)$ & $50(1.7)$ & $23(0.8)$ & $293(9.9)$ & \\
\hline Age $($ mean $\pm S D)$ & $69.40 \pm 6.37$ & $73.60 \pm 7.47$ & $76.51 \pm 6.59$ & $77.32 \pm 7.13$ & $79.88 \pm 6.78$ & $81.09 \pm 9.12$ & $77.84 \pm 7.22$ & $\mathrm{a}<\mathrm{b}<\mathrm{c}, \mathrm{d}, \mathrm{e}, \mathrm{f}$ \\
\hline Education & $9.14 \pm 5.25$ & $8.02 \pm 5.40$ & $7.12 \pm 5.23$ & $5.83 \pm 5.20$ & $4.22 \pm 4.95$ & $3.65 \pm 5.10$ & $5.73 \pm 5.25$ & $\mathrm{a}>\mathrm{b}>\mathrm{d}, \mathrm{e}, \mathrm{f}$ \\
\hline Gender (female, \%) & 50.0 & 55.2 & 65.4 & 75.9 & 74.0 & 70.8 & 72.3 & $\mathrm{a}<\mathrm{b}, \mathrm{c}, \mathrm{d}<\mathrm{e}$ \\
\hline GDS-KR & $8.23 \pm 5.62$ & $11.84 \pm 6.46$ & $11.83 \pm 6.60$ & $12.80 \pm 7.10$ & $13.62 \pm 8.58$ & $18.30 \pm 7.32$ & $12.89 \pm 7.29$ & $\mathrm{a}<\mathrm{b}, \mathrm{c}, \mathrm{d}, \mathrm{e}<\mathrm{f}$ \\
\hline SMCQ & $2.83 \pm 2.33$ & $5.28 \pm 3.13$ & $7.75 \pm 3.66$ & $8.55 \pm 3.73$ & $8.89 \pm 4.87$ & $11.62 \pm 4.11$ & $8.55 \pm 3.98$ & $\mathrm{a}<\mathrm{b}<\mathrm{c}, \mathrm{d}, \mathrm{e}<\mathrm{f}$ \\
\hline MMSE & $26.62 \pm 2.72$ & $23.86 \pm 4.14$ & $18.51 \pm 4.68$ & $15.38 \pm 4.75$ & $10.86 \pm 4.40$ & $6.67 \pm 3.97$ & $14.81 \pm 5.70$ & $a>b>c>d>e>f$ \\
\hline
\end{tabular}

NC: normal control, MCI: mild cognitive impairment, AD: Alzheimer's disease, CDR: clinical dementia rating, GDS-KR: Korean version of geriatric depression scale, SMCQ: subjective memory complaints questionnaire, MMSE: mini-mental status examination, SD: standard deviation 
Table 2. Disability assessment for dementia (DAD) in normal controls and patients with mild cognitive impairment (MCI) and Alzheimer's disease (AD)

\begin{tabular}{|c|c|c|c|c|c|c|c|}
\hline & \multirow{2}{*}{$\mathrm{NC}^{\mathrm{a}}$} & \multirow{2}{*}{$\mathrm{MCI}^{\mathrm{b}}$} & \multicolumn{4}{|c|}{$\mathrm{AD}$} & \multirow{2}{*}{ Posthoc } \\
\hline & & & $\mathrm{CDR} 0.5^{\mathrm{c}}$ & $\mathrm{CDR} 1^{\mathrm{d}}$ & $\mathrm{CDR} 2^{\mathrm{e}}$ & $\mathrm{CDR} \geq 3^{\mathrm{f}}$ & \\
\hline BADL & $99.84 \pm 5.99$ & $99.63 \pm 3.63$ & $97.31 \pm 9.40$ & $82.72 \pm 23.61$ & $48.85 \pm 32.98$ & $30.36 \pm 29.50$ & $a, b, c>d>e>f$ \\
\hline Hygiene & $99.81 \pm 3.43$ & $99.52 \pm 4.82$ & $95.77 \pm 16.36$ & $77.44 \pm 34.65$ & $39.26 \pm 41.24$ & $19.05 \pm 31.15$ & $a, b, c>d>e>f$ \\
\hline Dressing & $99.82 \pm 3.69$ & $99.60 \pm 4.33$ & $98.27 \pm 8.48$ & $81.07 \pm 28.46$ & $50.00 \pm 40.85$ & $28.13 \pm 34.54$ & $a, b, c>d>e>f$ \\
\hline Continence & $99.87 \pm 3.24$ & $99.66 \pm 4.10$ & $99.38 \pm 5.56$ & $96.53 \pm 4.06$ & $72.00 \pm 41.85$ & $56.25 \pm 42.51$ & $a, b, c>d>e>f$ \\
\hline Eating & $99.92 \pm 2.37$ & $99.77 \pm 3.88$ & $97.94 \pm 9.64$ & $88.74 \pm 23.97$ & $54.33 \pm 40.24$ & $43.75 \pm 42.22$ & $a, b, c>d>e>f$ \\
\hline IADL & $99.60 \pm 3.70$ & $97.89 \pm 9.70$ & $79.54 \pm 24.84$ & $47.58 \pm 34.69$ & $16.23 \pm 21.72$ & $8.16 \pm 11.33$ & $a, b>c>d>e, f$ \\
\hline Meal preparation & $99.62 \pm 5.84$ & $98.73 \pm 10.84$ & $82.61 \pm 35.52$ & $55.12 \pm 44.72$ & $8.77 \pm 21.48$ & $7.02 \pm 23.78$ & $\mathrm{a}, \mathrm{b}>\mathrm{c}>\mathrm{d}>\mathrm{e}, \mathrm{f}$ \\
\hline Telephoning & $99.57 \pm 4.98$ & $97.74 \pm 11.40$ & $86.95 \pm 21.87$ & $57.36 \pm 38.76$ & $18.64 \pm 30.66$ & $2.50 \pm 7.69$ & $a, b>c>d>e, f$ \\
\hline Going on an outing & $99.84 \pm 3.06$ & $98.31 \pm 12.15$ & $78.51 \pm 36.10$ & $45.45 \pm 41.56$ & $18.26 \pm 29.78$ & $3.41 \pm 15.99$ & $a, b>c>d>e, f$ \\
\hline Finance and correspondence & $99.33 \pm 7.02$ & $97.91 \pm 11.74$ & $67.12 \pm 44.44$ & $40.01 \pm 43.64$ & $20.28 \pm 35.67$ & $1.96 \pm 8.08$ & $a, b>c>d>e, f$ \\
\hline Medication & $99.80 \pm 4.39$ & $97.48 \pm 14.50$ & $70.15 \pm 41.80$ & $42.86 \pm 46.93$ & $7.95 \pm 23.98$ & $11.36 \pm 35.60$ & $a, b>c>d>e, f$ \\
\hline Leisure and housework & $99.64 \pm 4.47$ & $98.40 \pm 10.18$ & $86.49 \pm 25.23$ & $49.71 \pm 39.68$ & $22.43 \pm 29.94$ & $19.79 \pm 1.84$ & $a, b>c>d>e, f$ \\
\hline Initiation & $99.67 \pm 4.27$ & $99.06 \pm 5.05$ & $89.59 \pm 15.84$ & $68.96 \pm 26.27$ & $35.96 \pm 6.31$ & $23.04 \pm 24.36$ & $a, b>c>d>e>f$ \\
\hline Planning and organization & $99.41 \pm 4.97$ & $98.82 \pm 5.90$ & $86.58 \pm 18.41$ & $59.33 \pm 31.44$ & $26.82 \pm 23.92$ & $13.96 \pm 17.01$ & $a, b>c>d>e, f$ \\
\hline Performance & $99.58 \pm 4.65$ & $98.56 \pm 7.83$ & $87.21 \pm 15.66$ & $63.49 \pm 27.79$ & $32.46 \pm 24.48$ & $17.67 \pm 19.82$ & $a, b>c>d>e>f$ \\
\hline DAD-K total score & $99.59 \pm 4.47$ & $98.75 \pm 6.26$ & $87.83 \pm 15.48$ & $64.28 \pm 26.75$ & $32.46 \pm 23.35$ & $18.75 \pm 19.03$ & $a, b>c>d>e>f$ \\
\hline
\end{tabular}

NC: normal control, CDR: clinical dementia rating, BADL: basic activity of daily living, IADL: instrumental activity of daily living

Table 3. Receiver operator characteristics of disability assessment for dementia (DAD) for mild cognitive impairment (MCl) and Alzheimer's disease $(A D)$

\begin{tabular}{|c|c|c|c|c|c|c|}
\hline & AUC & SE & $95 \% \mathrm{CI}$ & Cut-off score & Sensitivity & Specificity \\
\hline \multicolumn{7}{|l|}{$\mathrm{NC}$ versus $\mathrm{MCI}$ or $\mathrm{AD}$} \\
\hline Total & 0.737 & 0.014 & $0.710-0.763$ & 99.00 & 0.964 & 0.497 \\
\hline BADL & 0.631 & 0.014 & $0.603-0.659$ & 97.26 & 0.994 & 0.268 \\
\hline IADL & 0.734 & 0.014 & $0.707-0.761$ & 97.83 & 0.969 & 0.488 \\
\hline Initiation & 0.704 & 0.014 & $0.677-0.732$ & 96.00 & 0.984 & 0.420 \\
\hline Planning and organization & 0.699 & 0.014 & $0.671-0.726$ & 95.00 & 0.983 & 0.410 \\
\hline Performance & 0.723 & 0.014 & $0.696-0.751$ & 97.00 & 0.977 & 0.462 \\
\hline \multicolumn{7}{|l|}{ NC versus $A D$} \\
\hline Total & 0.927 & 0.012 & $0.904-0.951$ & 99.00 & 0.964 & 0.866 \\
\hline BADL & 0.760 & 0.019 & $0.722-0.797$ & 97.06 & 0.994 & 0.524 \\
\hline IADL & 0.925 & 0.012 & $0.901-0.949$ & 97.83 & 0.969 & 0.859 \\
\hline Initiation & 0.890 & 0.014 & $0.861-0.918$ & 96.00 & 0.984 & 0.786 \\
\hline Planning and organization & 0.877 & 0.015 & $0.848-0.907$ & 95.00 & 0.983 & 0.762 \\
\hline Performance & 0.911 & 0.013 & $0.885-0.937$ & 97.00 & 0.977 & 0.831 \\
\hline \multicolumn{7}{|l|}{$\mathrm{NC}$ or $\mathrm{MCI}$ versus $\mathrm{AD}$} \\
\hline Total & 0.911 & 0.013 & $0.885-0.937$ & 96.00 & 0.936 & 0.824 \\
\hline BADL & 0.755 & 0.021 & $0.715-0.796$ & 97.06 & 0.983 & 0.524 \\
\hline IADL & 0.907 & 0.014 & $0.880-0.933$ & 95.35 & 0.902 & 0.852 \\
\hline Initiation & 0.878 & 0.015 & $0.847-0.908$ & 96.00 & 0.939 & 0.786 \\
\hline Planning and organization & 0.868 & 0.016 & $0.836-0.900$ & 95.00 & 0.936 & 0.762 \\
\hline Performance & 0.896 & 0.014 & $0.867-0.924$ & 97.00 & 0.899 & 0.831 \\
\hline
\end{tabular}

NC: normal control, CDR: clinical dementia rating, BADL: basic activity of daily living, IADL: instrumental activity of daily living, AUC: area under receiver operator characteristics curve, SE: standard error 
not significantly correlated with the BADL score, initiation, performance or DAD-K total score $(\mathrm{r}=-0.013, \mathrm{p}=0.512$; $\mathrm{r}=-$ $0.002, \mathrm{p}=0.928 ; \mathrm{r}=-0.030, \mathrm{p}=0.140$; and $\mathrm{r}=-0.018, \mathrm{p}=0.383$, re-

Table 4. Normal control demographics

\begin{tabular}{lccc}
\hline & Male & Female & Total \\
\hline Number & 1181 & 1181 & 2362 \\
Age (year)* & $69.23 \pm 6.27$ & $69.58 \pm 6.46$ & $69.40 \pm 6.37$ \\
$60-64^{\dagger}$ & $313(26.5)$ & $324(27.4)$ & $637(27.0)$ \\
$65-69$ & $346(29.3)$ & $309(26.2)$ & $655(27.7)$ \\
$70-74$ & $295(25.0)$ & $283(24.0)$ & $578(24.5)$ \\
$75-79$ & $155(13.1)$ & $170(14.4)$ & $325(13.8)$ \\
$80-84$ & $47(4.0)$ & $67(5.7)$ & $114(4.8)$ \\
$85-$ & $25(2.1)$ & $28(2.4)$ & $53(2.2)$ \\
Education (year)* & $11.16 \pm 4.73$ & $7.13 \pm 4.98$ & $9.14 \pm 5.25$ \\
$0^{\dagger}$ & $37(3.1)$ & $190(16.1)$ & $227(9.6)$ \\
$1-3$ & $40(3.4)$ & $120(10.2)$ & $160(6.8)$ \\
$4-6$ & $199(16.9)$ & $370(31.3)$ & $596(24.1)$ \\
$7-9$ & $195(16.5)$ & $145(12.3)$ & $340(14.4)$ \\
$10-12$ & $282(23.9)$ & $213(18.0)$ & $495(21.0)$ \\
$13-$ & $428(36.2)$ & $143(12.1)$ & $571(24.2)$ \\
\hline
\end{tabular}

${ }^{*}$ mean \pm standard deviation, ${ }^{\dagger}$ number (percentage) spectively). Education was highly correlated with the IADL score, DAD-K total score, initiation, planning and organization and performance $(\mathrm{r}=0.078, \mathrm{p}<0.001 ; \mathrm{r}=0.053, \mathrm{p}=0.010$; $\mathrm{r}=$ $0.048, \mathrm{p}=0.019 ; \mathrm{r}=0.068, \mathrm{p}=0.001$; and $\mathrm{r}=0.055, \mathrm{p}=0.008$, respectively). Education was not significantly correlated with the BADL score $(r=-0.026, p=0.200)$. In the $t$-test analysis, the BADL score, IADL score, DAD-K total score, initiation, planning and organization and performance were comparable between both genders $[\mathrm{t}(2357)=1.247, \mathrm{p}=0.213 ; \mathrm{t}(2358)=782$, $\mathrm{p}=0.434 ; \mathrm{t}(2358)=0.440, \mathrm{p}=0.660 ; \mathrm{t}(2358)=507, \mathrm{p}=0.613 ; \mathrm{t}$ $(2357)=302, \mathrm{p}=0.762$; and $\mathrm{t}(2358)=1.034, \mathrm{p}=0.301$, respectively].

Gender factor among demographics was excluded in multiple regression analyses because gender was not significantly related with DAD-K performance. The BADL score was not significantly influenced by age and education. However, the IADL score, DAD-K total score, initiation and performance were significantly influenced by education $\left(\mathrm{R}^{2}=0.6, \mathrm{p}<0.001\right.$; $\mathrm{R}^{2}=0.3, \mathrm{p}=0.010 ; \mathrm{R}^{2}=0.2, \mathrm{p}=0.019$; and $\mathrm{R}^{2}=0.3, \mathrm{p}=0.008$, respectively). The planning and organization score was significantly accounted for by age and education $\left(\mathrm{R}^{2}=0.2, \mathrm{p}=0.026\right.$ and $\mathrm{R}^{2}=0.5, \mathrm{p}=0.006$, respectively).

The results of the $3 \times 6$ ANOVA are as follows: No main or

Table 5. Normative data of disability assessment for dementia (DAD) in elderly Koreans

\begin{tabular}{|c|c|c|c|c|}
\hline & Number & $\mathrm{M} \pm \mathrm{SD}$ & Median (5\%ile) & $-1.5 \mathrm{SD}$ \\
\hline BADL & 2359 & $99.8 \pm 1.0$ & $100(100)$ & 98.3 \\
\hline \multicolumn{5}{|l|}{$\mathrm{IADL}$} \\
\hline \multicolumn{5}{|l|}{ Education $0-3$ yrs } \\
\hline $60-74$ yrs & 242 & $99.3 \pm 1.0$ & $100(95.3)$ & 99.3 \\
\hline $65-79$ yrs & 283 & $99.3 \pm 1.0$ & $100(95.2)$ & 99.3 \\
\hline $70-84$ yrs & 255 & $98.7 \pm 1.1$ & $100(90.9)$ & 98.7 \\
\hline $75-$ yrs & 145 & $97.8 \pm 1.1$ & $100(87.9)$ & 97.8 \\
\hline Education $\geq 4$ yrs & 1973 & $99.7 \pm 1.0$ & $100(100)$ & 99.7 \\
\hline Initiation & 2360 & $99.7 \pm 1.0$ & $100(100)$ & 99.7 \\
\hline \multicolumn{5}{|l|}{ Planning-organization } \\
\hline \multicolumn{5}{|l|}{ Education $0-3$ yrs } \\
\hline $60-79$ yrs & 330 & $99.4 \pm 1.0$ & $100(100)$ & 99.4 \\
\hline $70-84$ yrs & 255 & $98.8 \pm 1.1$ & $100(89.0)$ & 98.8 \\
\hline $75^{-}$yrs & 18 & $98.0 \pm 1.1$ & $100(82.3)$ & 98.0 \\
\hline Education $\geq 4$ yrs & 1862 & $99.8 \pm 1.0$ & $100(100)$ & 99.8 \\
\hline \multicolumn{5}{|l|}{ Performance } \\
\hline Education $0-3$ yrs & 387 & $99.1 \pm 1.0$ & $100(94.0)$ & 99.1 \\
\hline Education $\geq 4$ yrs & 1973 & $99.7 \pm 1.0$ & $100(100)$ & 99.7 \\
\hline \multicolumn{5}{|l|}{ Total score } \\
\hline Education $0-3$ yrs & 387 & $99.2 \pm 1.0$ & $100(95.0)$ & 99.2 \\
\hline Education $\geq 4$ yrs & 1973 & $99.7 \pm 1.0$ & $100(100)$ & 99.7 \\
\hline
\end{tabular}

M \pm SD: mean \pm standard deviation, BADL: basic activity of daily living, IADL: instrumental activity of daily living 
interaction effects were found between the BADL scores and demographics variables $(\mathrm{F}=0.866, \mathrm{p}=0.421 ; \mathrm{F}=1.466, \mathrm{p}=$ 0.198 ; and $\mathrm{F}=0.624, \mathrm{p}=0.794$, respectively). The main effects of age and education, and the interaction effects between age and education were significant on the IADL score $(\mathrm{F}=6.338$, $\mathrm{p}=0.002 ; \mathrm{F}=12.846, \mathrm{p}<0.001$; and $\mathrm{F}=4.504, \mathrm{p}<001$, respectively). The main effect of education and the interaction effects between age and education were significant on the DAD-K total scores $(\mathrm{F}=5.215, \mathrm{p}<0.001$ and $\mathrm{F}=1.968, \mathrm{p}=0.033$, respectively). The main effect of education was significant on the initiation score $(\mathrm{F}=2.245, \mathrm{p}=0.047)$. The main effects of age and education and the interaction between age and education were significant on the planning and organization score $(\mathrm{F}=3.924$, $\mathrm{p}=0.020 ; \mathrm{F}=5.584, \mathrm{p}<0.001$; and $\mathrm{F}=2.883, \mathrm{p}=0.001$, respectively). The main effect of education and the interaction effects between age and education were significant on the performance scores $(\mathrm{F}=4.855, \mathrm{p}<0.001$ and $\mathrm{F}=1.999, \mathrm{p}=0.030$, respectively).

In summary, the BADL score was not influenced by age and education; however, the IADL score was significantly influenced by age and education, and the DAD-K total score was significantly influenced by education. In terms of executive functioning (i.e., initiation, planning and organization, and performance) the initiation and performance scores were significantly influenced by education, and the planning and organization score was significantly influenced by age and education. Therefore, we provided mean, standard deviation, median and the 5th percentile of the BADL score as unitary scores that were not classified by demographic factors (Table 5). Mean, standard deviation, median and the 5th percentile score of the IADL score and the planning and organization score classified by age and education were provided (Table 5). Even though initiation score was influenced by education, it was not significant in the post hoc analysis. Thus, mean, standard deviation, median and the 5th percentile score of the initiation score were provided as unitary scores (Table 5). Mean, standard deviation, median and the 5 th percentile score of the DAD-K total and performance scores were stratified by education (Table 5). To develop normative data for IADL, the total group was divided into four overlapping age tables and two strata of educational levels ( $0-3, \geq 4$ years). The educational strata were determined by first considering the results from the post hoc contrasts between the educational groups, which indicated significant differences between the lowest groups (i.e., 0 vs. $4-6,0$ vs. $10-12$, or 0 vs. $\geq 13$ years) and no significant differences between the lower educational groups (i.e., 0 vs. $1-3$ ). The number of subjects within each cell required for stable estimation of normative value was also taken into account. Overlapping cell tables with midpoint ages occurring at 5-year intervals from 67 to 82 years (i.e., 67, 72, 77, and 82) were developed. The age range from which each normative value was estimated was 14 years (i.e., \pm 7 years around the midpoint age) for each table and the ranges for the adjacent tables are overlapped (i.e., 60-74, 65-79, 70-84, and $\geq 75$ ). To interpret the test scores, the user should select the table with the closest midpoint from the subject's age.

\section{DISCUSSION}

We investigated the influences of age, education, and gender on $\mathrm{DAD}-\mathrm{K}$ performance and developed normative data for the $\mathrm{DAD}-\mathrm{K}$ from a large, nationally representative, community-dwelling elderly Korean population. In addition, we examined the usefulness of DAD-K in differentiating patients with MCI and/or AD from NCs.

Patients with $\mathrm{MCI}$ or very mild $\mathrm{AD}(\mathrm{CDR}=0.5)$ and $\mathrm{NCs}$ had comparable BADL total scores; however, patients with mild or severer $\mathrm{AD}(\mathrm{CDR} \geq 1)$ had significantly lower BADL total scores than that of the NCs. Moreover, patients with MCI and NCs had comparable IADL total scores; however, patients with very mild or severer $\mathrm{AD}(\mathrm{CDR} \geq 0.5)$ had significantly lower IADL total scores than that of the NCs. This indicated that the decrease in the IADL performance preceded the decrease in the function of BADL performance, which is consistent with the results of a previous study. ${ }^{18}$ Communitydwelling patients with MCI had a significantly lower annual conversion rate to $\mathrm{AD}$ and a low degree of functional impairment at baseline than that of the clinic-based patients with MCI. ${ }^{32}$

The number of IADL items that the patients could perform in the DAD-K effectively differentiated the patients with MCI from those with AD (AUC=0.909). The optimal cut-off was $18 / 19$, where sensitivity and specificity were $85.8 \%$ and $82.2 \%$, respectively. In a previous work, the DAD-6 scale, which consisted of 6 IADL items of the DAD, also differentiated patients with $\mathrm{AD}$ from individuals with $\mathrm{MCI}$ (AUC= 0.900 , optimal cut-off $=14)$. $^{33}$

Consistent with a previous study, ${ }^{18}$ the total DAD-K score was not significantly correlated with age, gender and education. Deeper analysis revealed that the total IADL score was correlated with age and education. However, the influence of demographic factors on DAD-K scores was not obvious as compared with other neuropsychological tests developed for elderly Koreans. ${ }^{31,34}$

Comparing the raw score of detailed DAD-K items between the NC and MCI groups, there were no significant differences. To modify negatively skewed data, we performed log transformation with these raw scores. This revealed significant differences in the IADL total scores of DAD-K between the NC and MCI groups, but the differentiating power was low (AUC= 
0.546). Although log transformation revealed significant differences in some DAD-K subscales, low differentiation power and highly skewed scores toward ceiling in NCs suggested some difficulties in the practical application of our norm in differentiating NC from MCI. The 5th percentile of the IADL and planning and organization scores in some stratified groups, like less educated ( $0-3$ years) and $>69$ years old, can be applied to differentiate NC from MCI. In BADL, initiation, performance and total DAD-K scores and in IADL and planning and organization scores of other demographic populations, bad performance on only one item can be interpreted as abnormal. Although the discrimination power could be low, unitary or minimally stratified our DAD-K norm is advantageous because of its easy application and interpretation.

The logistic regression analysis showed that there were significant differences between the NC and MCI groups on the IADLs, such as the ability to use the telephone and perform leisure activities/hobbies. It seems that patients with MCI have limitations in performing everyday tasks that involve memory and frontal/executive functioning. This results are partially consistent with a previous study that demonstrated that IADLs, such as the ability to use the telephone $(\mathrm{OR}=10.55)$ and to perform leisure activities/hobbies $(\mathrm{OR}=3.01)$, were decreased in patients with MCI than in the NCs. ${ }^{5}$ However in this previous study, the ability of preparing meals, taking medication, managing belongings, keeping appointments and talking about recent events were also decreased in patients with MCI than in NCs, although both this study and our current study targeted Korean elders. These differences might be partially because the characteristics of MCI group were different between the two studies. In the Seoul-IADL study, ${ }^{5} \mathrm{pa}-$ tients with MCI were recruited from the visitors to the geropsychiatry clinic at the department of psychiatry at the Samsung Medical Center in Seoul and these participants might have had more functional impairments than the participants with $\mathrm{MCI}$ in the present study.

Our study has several limitations. The participants are unlikely to be representative of the entire MCI population and selection of International working group MCI criteria rather than National Institute on Aging-Alzheimer's Association workgroups MCI criteria, ${ }^{35}$ in which some degree of functional impairment is allowed might contribute to our results. The cross-sectional design is another limitation. An extended longitudinal study is needed to confirm the results.

In conclusion, our findings suggest that the DAD-K scale, which evaluates complex ADL based on an informant interview, can effectively differentiate between patients with MCI and $\mathrm{AD}$. Moreover, $\mathrm{DAD}-\mathrm{K}$ can be used to evaluate functional impairment in MCI by using established log rank IADL norms.

\section{Acknowledgments}

This study was supported by Korean Health Technology R\&D Project grant from the Ministry for Health, Welfare and Family Affairs, Republic of Korea (Grant No. A092077).

\section{REFERENCES}

1. Petersen RC, Smith GE, Waring SC, Ivnik RJ, Tangalos EG, Kokmen E. Mild cognitive impairment: clinical characterization and outcome. Arch Neurol 1999;56:303-308.

2. Perneczky R, Pohl C, Sorg C, Hartmann J, Komossa K, Alexopoulos P, et al. Complex activities of daily living in mild cognitive impairment: conceptual and diagnostic issues. Age Ageing 2006;35:240-245.

3. Perneczky R, Pohl C, Sorg C, Hartmann J, Tosic N, Grimmer T, et al. Impairment of activities of daily living requiring memory or complex reasoning as part of the MCI syndrome. Int J Geriatr Psychiatry 2006; 21:158-162.

4. Winblad B, Palmer K, Kivipelto M, Jelic V, Fratiglioni L, Wahlund LO, et al. Mild cognitive impairment--beyond controversies, towards a consensus: report of the International Working Group on Mild Cognitive Impairment. J Intern Med 2004;256:240-246.

5. Ahn IS, Kim JH, Kim S, Chung JW, Kim H, Kang HS, et al. Impairment of instrumental activities of daily living in patients with mild cognitive impairment. Psychiatry Investig 2009;6:180-184.

6. Tabert MH, Albert SM, Borukhova-Milov L, Camacho Y, Pelton G, Liu $\mathrm{X}$, et al. Functional deficits in patients with mild cognitive impairment: prediction of AD. Neurology 2002;58:758-764.

7. Han JW, Lee SB, Kim TH, Park JH, Lee JJ, Huh YS, et al. Functional impairment in the diagnosis of mild cognitive impairment. Alzheimer Dis Assoc Disord 2011;25:225-229.

8. Brown PJ, Devanand DP, Liu X, Caccappolo E; Alzheimer's Disease Neuroimaging Initiative. Functional impairment in elderly patients with mild cognitive impairment and mild Alzheimer disease. Arch Gen Psychiatry 2011;68:617-626.

9. Barberger-Gateau P, Fabrigoule C, Helmer C, Rouch I, Dartigues JF. Functional impairment in instrumental activities of daily living: an early clinical sign of dementia? J Am Geriatr Soc 1999;47:456-462.

10. Peres K, Chrysostome V, Fabrigoule C, Orgogozo JM, Dartigues JF, Barberger-Gateau P. Restriction in complex activities of daily living in MCI: impact on outcome. Neurology 2006;67:461-466.

11. Verbrugge LM, Jette AM. The disablement process. Soc Sci Med 1994; 38:1-14.

12. Katz S. Assessing self-maintenance: activities of daily living, mobility, and instrumental activities of daily living. J Am Geriatr Soc 1983;31: 721-727.

13. Lawton MP, Brody EM. Assessment of older people: self-maintaining and instrumental activities of daily living. Gerontologist 1969;9:179-186.

14. Hindmarch I, Lehfeld H, de Jongh P, Erzigkeit H. The Bayer Activities of Daily Living Scale (B-ADL). Dement Geriatr Cogn Disord 1998;9(Suppl 2):20-26.

15. Petersen RC. Mild cognitive impairment as a diagnostic entity. J Intern Med 2004;256:183-194.

16. Rozzini L, Chilovi BV, Conti M, Bertoletti E, Delrio I, Trabucchi M, et al. Conversion of amnestic Mild Cognitive Impairment to dementia of Alzheimer type is independent to memory deterioration. Int J Geriatr Psychiatry 2007;22:1217-1222.

17. Fisk JD, Merry HR, Rockwood K. Variations in case definition affect prevalence but not outcomes of mild cognitive impairment. Neurology 2003;61:1179-1184.

18. Gelinas I, Gauthier L, McIntyre M, Gauthier S. Development of a functional measure for persons with Alzheimer's disease: the disability assessment for dementia. Am J Occup Ther 1999;53:471-481.

19. Mok CC, Siu AM, Chan WC, Yeung KM, Pan PC, Li SW. Functional disabilities profile of chinese elderly people with Alzheimer's disease a validation study on the chinese version of the disability assessment 
for dementia. Dement Geriatr Cogn Disord 2005;20:112-119.

20. Bahia VS, Carthery-Goulart MT, Novelli MM, Kato-Narita EM, ArezaFegyveres R, Caramelli P, et al. Functional disability in Alzheimer disease: a validation study of the Brazilian version of the Disability Assessment for Dementia (DAD-Br). Alzheimer Dis Assoc Disord 2010;24: 291-295.

21. De Vreese LP, Caffarra P, Savare R, Cerutti R, Franceschi M, Grossi E, et al. Functional disability in early Alzheimer's disease - a validation study of the Italian version of the disability assessment for dementia scale. Dement Geriatr Cogn Disord 2008;25:186-194.

22. Suh GH. Development of the Korean Version of Disability Assessment for Dementia Scale(DAD-K) to assess function in dementia. J Korean Geriatr Soc 2003;7:278-287.

23. Kim TH, Park JH, Lee JJ, Jhoo JH, Kim BJ, Kim JL, et al. Overview of the Korean longitudinal study on cognitive aging and dementia. Alzheimers Dement 2013; 9(Suppl 4):626-627.

24. Hughes CP, Berg L, Danziger WL, Coben LA, Martin RL. A new clinical scale for the staging of dementia. Br J Psychiatry 1982;140:566-572.

25. Lee JH, Lee KU, Lee DY, Kim KW, Jhoo JH, Kim JH, et al. Development of the Korean version of the Consortium to Establish a Registry for Alzheimer's Disease Assessment Packet (CERAD-K): clinical and neuropsychological assessment batteries. J Gerontol B Psychol Sci Soc Sci 2002;57:47-53.

26. McKhann G, Drachman D, Folstein M, Katzman R, Price D, Stadlan EM. Clinical diagnosis of Alzheimer's disease: report of the NINCDSADRDA Work Group under the auspices of Department of Health and Human Services Task Force on Alzheimer's Disease. Neurology 1984;34:939-944.

27. Suh GH. Validation of the Korean version of the Alzheimer's Disease Assessment Scale. J Korean Geriatr Soc 2003;7:267-277.
28. Kim JY, Park JH, Lee JJ, Huh Y, Lee SB, Han SK, et al. Standardization of the Korean version of the geriatric depression scale: reliability, validity, and factor structure. Psychiatry Investig 2008;5:232-238.

29. Kim TH, Jhoo JH, Park JH, Kim JL, Ryu SH, Moon SW, et al. Korean version of mini mental status examination for dementia screening and its' short form. Psychiatry Investig 2010;7:102-108.

30. Youn JC, Kim KW, Lee DY, Jhoo JH, Lee SB, Park JH, et al. Development of the Subjective Memory Complaints Questionnaire. Dement Geriatr Cogn Disord 2009;27:310-317.

31. Jeong JW, Kim KW, Lee DY, Lee SB, Park JH, Choi EA, et al. A normative study of the Revised Hasegawa Dementia Scale: comparison of demographic influences between the Revised Hasegawa Dementia Scale and the Mini-Mental Status Examination. Dement Geriatr Cogn Disord 2007;24:288-293.

32. Han JW, Lee SB, Kim TH, Park JH, Lee JJ, Huh YS, et al. Functional impairment in the diagnosis of mild cognitive impairment. Alzheimer Dis Assoc Disord 2011;25:225-229.

33. de Rotrou J, Wu YH, Hugonot-Diener L, Thomas-Antrion C, Vidal JS, Plichart M, et al. DAD-6: a 6-item version of the Disability Assessment for Dementia scale which may differentiate Alzheimer's disease and mild cognitive impairment from controls. Dement Geriatr Cogn Disord 2012;33:210-218.

34. Lee DY, Lee KU, Lee JH, Kim KW, Jhoo JH, Kim SY, et al. A normative study of the CERAD neuropsychological assessment battery in the Korean elderly. J Int Neuropsychol Soc 2004;10:72-81.

35. Albert MS, DeKosky ST, Dickson D, Dubois B, Feldman HH, Fox NC, et al. The diagnosis of mild cognitive impairment due to Alzheimer disease: recommendations from the National Institute on Aging-Alzheimer's Association workgroups on diagnostic guidelines for Alzheimer's disease. Alzheimers Dement 2011;7:270-279. 